\title{
Discriminação racial e (re)construção nacional em Moçambique: O Alegre Canto da Perdiz, de Paulina Chiziane
}

\author{
Racial discrimination and national (re) \\ construction in Mozambique: O Alegre Canto da \\ Perdiz, by Paulina Chiziane
}

\section{DORIS UIESER *}

Resumo: Neste ensaio analiso os efeitos da discriminação racial colonial em Moçambique e as suas consequências na época pós-independência, em O alegre canto da perdiz (2008), de Paulina Chiziane. A análise inspira-se nos "espaços semânticos" de Jurij Lotman e nos "cronotopos" de Mikhail Bakhtin. Identificam-se assim um espaço mítico, um espaço histórico (colonial e pós-colonial) e um espaço do futuro imaginado, e questiona-se o papel destes espaços para à construção de uma identidade nacional.

Palavras-chave: Literatura moçambicana, racismo, identidade nacional, Paulina Chiziane.

\begin{abstract}
In this essay, It is analyzed the effects of colonial racial discrimination in Mozambique and its consequences in the post-independence era, in $O$ alegre canto da perdiz (2008) by Paulina Chiziane. The analysis is based on the "semantic spaces" of Jurij Lotman and the "chronotopes" of Mikhail Bakhtin. Thus, It is identified a mythical space, a historical space (colonial and post-colonial) and a space of imagined future. Afterwards It is questioned the role of these spaces for the construction of a national identity.
\end{abstract}

Keywords: Mozambican literature, racism, national identity, Paulina Chiziane.

\footnotetext{
* Professora Auxiliar no Departamento de Filologia Românica da Universidade de Göttingen e Pós-doutoranda da Fundação Alexander von Humboldt, no CESA (ISEG) e na Faculdade de Letras da Universidade de Lisboa (2014-2016).
} 


\section{- Introdução}

A identidade (seja individual, coletiva ou nacional ${ }^{2}$ ) mantém, historicamente, uma relação conflituosa com a cor da pele. Hoje em dia estamos acostumados, por razões de caráter político-histórico, a dissociar nitidamente questões de identidade e de "raça". ${ }^{3}$ É-nos impossível conceber a identidade com base numa essência genética, seja ela qual for, devido à profunda conviç̧ão construtivista dos nossos tempos. Porém, em Moçambique, as gerações que atualmente se encontram em plena atividade profissional e política ainda nasceram na "Província ultramarina de Moçambique". ${ }^{4}$ Portanto, estes cidadãos passaram por processos de socialização específicos na infância e juventude, dependendo da sua cor da pele. Nos tempos em que a lei distinguia entre brancos, mestiços, assimilados e indígenas ${ }^{5}$, a cor da pele cunhava não só o estatuto social, mas também a identidade das pessoas de uma maneira violenta. Portanto, é compreensível que apenas 40 anos após o fim do colonialismo português, que no século XX adquiriu caraterísticas do apartheid e estabeleceu uma "barreira biológica de identidade" (ZAMPARONI, 2006, p. 147), certos ressentimentos racistas não tenham desaparecido por completo.

Paulina Chiziane dedicou um romance inteiro ao tema da discriminação racial colonial e a sua implicação social até aos nossos dias. O Alegre Canto da Perdiz, publicado em 2008, desempenha uma função importante para a "memória

\footnotetext{
2 Entenda-se como "identidade nacional" um tipo particular de "identidade coletiva".

3 Optamos pelas aspas porque não há nenhuma base científica que justifique postular a existência de "raças" humanas. "Raça" é antes uma categoria discursiva que genética (HALL 2006: 62s.).

4 As "colónias" portuguesas em África foram rebatizadas "províncias ultramarinas" em 1951 devida à pressão internacional das nações que favoreciam a descolonização. Para os pormenores do debate político veja Castelo (2011: 48-61).

5 Sobre o variável uso destes termos veja Zamparoni (2006). No século XX, Portugal (tal como a França) estabeleceu uma legislação que visava a assimilação dos colonizados ("indígenas" e "mestiços") à cultura portuguesa. A Portaria Provincial n 317 de 9 de janeiro de 1917 introduziu o estatuto do "assimilado aos europeus". Para adquirir o alvará de assimilado era necessário cumprir com uma série de requisitos rígidos e difíceis de alcançar. Segundo Zamparoni, a Portaria perseguia o objetivo de melhor controlar e excluir os indígenas nas colónias. Na realidade esta legislação não ampliava os direitos de cidadania, mas limitava-os, ao isolar a elite de negros, a "pequena burguesia filha da terra" (ZAMPARONI, 2006, p. 150) tanto dos brancos como da massa dos indígenas comuns. Este espírito, embora os requisitos para a assimilação fossem atenuados em 1927, foi ratificado pelo Ato Colonial de 1930 (ZAMPARONI, 2006, p. 162-164).
} 
cultural" ${ }^{\prime}$ de Moçambique, na medida em que explica o presente através do passado e relembra que o passado colonial não pode ser visto "em branco e negro" no que diz respeito às diversas culpas.

O enredo do romance, apresentado por um narrador (ou uma narradora que toma partido pelas mulheres) omnisciente, desenrola-se na terra dos m'zambezi, mais precisamente entre o rio Licungo, ao Norte da cidade de Quelimane, e o Rio dos Bons Sinais (conhecido também como rio Cuácua), na província Zambézia, região central do país, onde as culturas patrilineares e matrilineares se misturam e, sobretudo, onde a miscigenação entre negros, brancos, árabes e indianos tem sido mais intensa. No romance, a Zambézia representa por extensão a nação moçambicana e até a humanidade inteira. Além do mais, a cidade de Gurué, ao pé dos montes sagrados de Namuli, desempenha um papel central no desfecho do enredo.

O romance dispõe de dois eixos temporais constituídos por um tempo histórico linear: o primeiro abrange a época do colonialismo durante o Estado Novo; o segundo centra-se num curto período da época pós-colonial, em que as diversas personagens se reencontram e enveredam pelo caminho do perdão. A estes eixos se acrescentam outros dois espaços temporais que se caraterizam por um tempo cíclico: o tempo dos mitos, contados pela mulher do régulo de Gurué (uma espécie de griot), e o tempo do futuro imaginado.

A protagonista do eixo do tempo histórico colonial é uma mulher negra, Delfina, pertencente à etnia dos chuabo, que se carateriza pela simbiose entre a cultura matrilinear e patrilinear. ${ }^{7}$ Delfina cresce num ambiente impregnado pelos processos políticos: seus três irmãos mais velhos foram deportados ${ }^{8}$ e a mãe obrigou-a a tornar-se prostituta. Porém, Delfina apaixona-se perdidamente por um homem também negro, José dos Montes, de um grupo cultural considera-

6 Para Jan Assmann a "memória cultural" compreende a dimensão externa da memória humana, isto é, a soma das memórias armazenadas externamente e, sobretudo, a tradição do seu significado. O termo abrange tanto os modos de lembrança como de esquecimento (ASSMANN, 2007, p. 19, 34).

7 Baseio-me no mapa etnográfico exposto no Museu Nacional de Etnografia de Nampula.

8 Depois do esclavagismo, o trabalho forçado (chibalo) veio substituir o trabalho do escravo. Acordos regionais permitiam a deportação dos trabalhadores forçados para o Transvaal (África do Sul), a Rodésia e também para a então colónia portuguesa de São Tomé e Príncipe (ZAMPARONI, 1998, p. 87). 
do inferior, os lomwe", além de possuir a condição de "condenado"10. Apesar da crítica da sua mãe Serafina ("Melhora a tua raça, minha Delfina", CHIZIANE, 2010, p. 96), ela decide casar-se com José e dá à luz uma filha em 1953, Maria das Dores, e mais tarde um filho (Zezinho). Delfina, mulher ambiciosa, exige que o marido se torne um "assimilado" para melhorar o estatuto social da família. ${ }^{11}$ Porém, após a assimilação, José vê-se forçado a trabalhar como sipaio ${ }^{12}$, o que implica maltratar os trabalhadores negros nas plantações e, numa expedição militar, matar gente da sua própria "raça". No entanto, Delfina consegue seduzir um colono português de nome Soares (homem casado e com filhos) e gera dois filhos mulatos (Jacinta e Luisinho), aos quais dará preferência doravante. Contudo, Soares não consegue abdicar da sua família portuguesa e decide voltar a Lisboa. Deixa uma generosa herança aos seus filhos mulatos, todavia não deixa nada à ávida Delfina, que depois de ser assaltada e roubada, fica sem quaisquer meios ou recursos. Começa então um relacionamento com o feiticeiro Simba, a quem mais tarde "vende" a sua filha primogénita Maria das Dores. Simba toma posse da menina de apenas 13 anos, droga-a, estupra-a e engravida-a. Aos seus 18 anos, Maria das Dores já tem três filhos (Rosinha, Benedito e Fernando) e consegue fugir da casa em 1974. Delfina, no entanto, volta à prostituição. Os seus dois filhos mulatos e Zezinho também fogem dela.

\footnotetext{
9 Serafina diz sobre ele: "Se ao menos fosse um Chuabo, que é um clã superior. Pelos vistos é um lomwe, um escravo qualquer, sem classe nem berço" (CHIZIANE, 2010, p. 107).

10 Ao lado do chibalo, um método de recrutar trabalhadores gratuitos foi o aprisionamento de indígenas "por bebedeira, desordem, desobediência e vagabundagem" (ZAMPARONI 1998: 90). A partir de 1916 estas infrações já não eram multadas senão convertidas em pena de trabalho correcional (ZAMPARONI, 1998, p. 87-93). No romance realça-se a maneira arbitrária e volúvel das autoridades, posto que José dos Montes é apanhado sem ter cometido crime nenhum: "O seu percurso é igual ao de todos os condenados. Foi caçado e acorrentado como um criminoso, sem saber o mal fizera [sic]" (CHIZIANE, 2010, p. 73).

11 A mulher e os filhos menores de dezoito anos passavam automaticamente à condição de assimilado do homem (ZAMPARONI, 2006, p. 149). Segundo Zamparoni os assimilados, "ao menos em tese, poderiam gozar dos mesmos direitos civis e administrativos dos colonos europeus como, por exemplo, receberem salários com base-ouro, [...] ou ter tratamento igualitário no acesso aos cargos e funções públicas que, entretanto, nunca passou de ilusão" (ZAMPARONI, 2006, p. 165.).

12 Os sipaios eram um tipo de polícia negra, a serviço dos postos administrativos. Entre as suas tarefas contava ajudar os régulos a recrutar homens para o chibalo e para as forças militares e de cobrar o imposto de palhota. Zamparoni considera-os "agentes diretos do aparelho de Estado, atuando como correias de transmissão dos novos valores impostos pelo dominador e desempenhando ativo papel na opressão de sua própria gente" (1998, p. 128).
} 
A narração começa e termina com o segundo eixo temporal (o tempo histórico pós-colonial), situando-se depois da guerra civil que constitui um hiato na biografia das personagens. A protagonista agora é Maria das Dores que está à procura dos seus filhos e erra nua e aparentemente louca pelas ruas de Gurué. No desfecho que apresenta as caraterísticas de uma anagnórise, todas as pessoas se reúnem, iniciam um diálogo de reconciliação e imaginam um futuro melhor.

\section{Análise: $O$ Alegre Canto da Perdiz}

Se focalizamos, em $O$ Alegre Canto da Perdiz, ${ }^{13}$ o espaço como espaço semântico (LOTMAN, ${ }^{4} 1993$ [1972]) ${ }^{14}$ e cronotópico (BAKHTIN, 1981) ${ }^{15}$, podemos constatar que se constitui por, pelo menos, três camadas: 1) um espaço de tempo mítico, 2) um espaço de tempo histórico (subdividido em tempo colonial e pós-colonial) e 3) um espaço do tempo futuro imaginado.

\subsection{0 espaço mítico}

O espaço mítico baseia-se numa série de mitos fundacionais do povo zambeziano. Para Assmann, um mito é uma estória contada com a finalidade de con-

13 Sobre este romance já foram publicados vários estudos. Questões de gênero são analisadas p. ex. por Miranda (2010), Teixeira (2010), Nascimento/Botelho (2013) e Braga (2013); a assimilação, mestiçagem e a repressão colonial são centro de interesse de Costa (2009), La Guardia/Goncalves (2010) e Khan (2013).

14 Lotman usa a bivalência inerente à nossa linguagem para postular fronteiras classificatórias e espacialmente metaforizadas que dividem o espaço semântico do mundo ficcional em diferentes subespaços que formam a "estrutura primária" do texto. A travessia de uma personagem de um subespaço a outro constitui um "acontecimento". Todos os "acontecimentos" em conjunto produzem uma "estrutura secundária" que se sobrepõe à "estrutura primária" e entra em conflito com ela: cria pontos de resistência contra o sistema binário discursivo restritivo (LOTMAN, 1993, p. 311-340).

15 Para Bakhtin, as caraterísticas do tempo em textos literários só se manifestam no espaço, e viceversa, o espaço só aufere dimensão e sentido através do tempo (BAKHTIN, 1981, p. 84). Partindo da investigação dos mecanismos da memória cultural, Assmann chega a um diagnóstico muito parecido quando afirma que a memória precisa de lugares e tende a expressar-se em espaços (ASSMANN, 2007, p. 39). 
ferir orientação em relação ao indivíduo e ao mundo, é uma verdade de ordem superior que reivindica constituir normas e possui força formativa (ASSMANN, 2007, p. 76). Além disso, os mitos estabelecem uma referência ao passado para iluminar a partir dali o presente e o futuro (ASSMANN, 2007, p. 78). O tempo mítico carateriza-se por estar situado num passado absoluto, desconectado dos eventos históricos. Além disso, é cíclico e sempre mantém a mesma distância do presente em progresso. $\mathrm{O}$ espaço mítico, no caso do romance, é congruente com o espaço geográfico real, a Zambézia, a região dos sagrados Montes Namuli, considerados "o berço da humanidade inteira" (CHIZIANE, 2010, p. 137). ${ }^{16}$

Com ajuda dos mitos, a mulher do régulo, que desempenha a função de portadora especializada da memória cultural, conforta os habitantes da vila que recorrem a ela quando Maria das Dores aparece nua e supostamente louca tomando banho no rio - espaço destinado aos homens. A transgressão de Maria provoca uma interpretação do subespaço histórico a partir da exegese dos mitos antigos. É significativo que o primeiro dos mitos referidos no romance parta de uma sociedade em que os dois sexos (ou gêneros) não convivem num espaço comum, mas em dois subespaços separados, e em que, ademais, as mulheres são felizes e exercem a sua supremacia sobre os homens. A felicidade das mulheres, porém, termina quando são seduzidas sexualmente pelos homens que, desta feita, conseguem usurpar o poder (CHIZIANE, 2010, p. 21s.). Tanto na Génesis bíblica como nestes mitos africanos, o início da desgraça da humanidade reside na sedução sexual e, por extensão, na promessa falsa de um amor feliz. Mas, nestes mitos, os papéis dos sexos são invertidos em relação a Adão e Eva. Quem seduz aqui é o homem e quem sucumbe e perde a felicidade é a mulher. Outro mito conta que Deus era uma mulher muito desejada pelos homens da terra. Mas quando a Deusa aceita ter relações sexuais descobre que "engravidou de apenas um" e que "afinal não tinha poderes para parir o universo inteiro" (CHIZIANE, 2010, p. 227), pelo que os homens a derrubam e reprimem todas as mulheres da terra. Um terceiro mito conta a vingança das mulheres que matam todos os homens, retomam o poder, mas não conseguindo resistir à beleza de um jovem,

16 La Guardia e Gonçalves (2010, p. 219) oferecem uma leitura metonímica dos Montes Namuli (representação do falo) e da Zambézia (representação da feminilidade) 
matam a rainha e fazem dele o rei (CHIZIANE, 2010, p. 269). ${ }^{17}$

Estes mitos, oriundos da mistura entre culturas matrilineares e patrilineares, fundamentam a identidade zambeziana (e, por extensão metonímica, moçambicana ou até africana), e interpretam o mundo como uma "guerra dos sexos" (CHIZIANE, 2010, p. 310) em que os papéis de dominação potencialmente se alternam eternamente. A mulher do régulo, poder interpretativo desta pequena comunidade, vê na aparição de Maria das Dores um sinal de esperança para as mulheres: "Uma mulher nua do lado dos homens? Ó gente, ela veio de um reino antigo para resgatar o nosso poder usurpado" (CHIZIANE, 2010, p. 22). O sistema patriarcal, predominante na grande maioria das culturas do planeta, implantado também pela colonização portuguesa, não é portanto encarado como um sistema imutável, mas como um estado potencialmente transitório.

Assmann distingue entre mitos que transcorrem no passado absoluto e mitos que se situam no passado histórico. Os primeiros realizam a semantização do cosmos, os segundos, da história. Os mitos situados no passado absoluto são caraterísticos das chamadas sociedades "frias" (sociedades tradicionais que aspiram ao equilíbrio e à continuidade) e aqueles situados no passado histórico encontram-se geralmente em sociedades "quentes" (sociedades que aspiram a desenvolver-se e progredir) (ASSMANN, 2007, p. 68-78). No romance de Paulina Chiziane encontramos também estes dois tipos. A mulher do régulo mitifica a história ao resumir o percurso do povo moçambicano, mencionando migrações, guerras e a miscigenação violenta, tanto antes como durante a colonização, desembocando no tempo presente das personagens: "As mulheres violadas choravam as dores do infortúnio com sementes no ventre, e deram à luz uma nova nação. Os invasores destruíram os nossos templos, nossos deuses, nossa língua. Mas com eles construímos uma nova língua, uma nova raça. Essa raça somos nós" (CHIZIANE, 2010, p. 23). Deste modo, as guerras pré-coloniais (entre grupos culturais distintos) e a colonização são interpretadas como a repetição dos mitos antigos na medida em que são encaradas como uma vitória dos homens sobre as mulheres.

17 Este mito pode também explicar a poligamia. Além dos mencionados o romance contém outros dois mitos (veja-se CHIZIANE, 2010, p. 279s. e p. 310s.). Os mitos são dominados essencialmente pela narração da perda do poder das mulheres, tendo pouco espaço as tentativas da recuperação do mesmo, mas isto não invalida a esperança da recuperação cíclica. 
O relato não deixa dúvidas quanto à função mítica (e tradicional) do amor que é a procriação e, portanto, a continuidade da comunidade. A mulher do régulo conta, em tom mitificante, a história da colonização em que a Zambézia se transforma alegoricamente em mulher e se torna vítima dos colonizadores-homens (os "marinheiros"): ${ }^{18}$

De todas as sereias a Zambézia era a mais bela. Os marinheiros invadiramna e a amaram-na amara-a [sic] furiosamente, como só se invade a mulher amada. A Zambézia bela, encantada, gritava em orgasmo pleno: vem, marinheiro, ama-me, eu te darei um filho. Eu e tu, sempre juntos, criando uma nova raça. Em todo o lado deixaremos marcas do nosso amor. Deixaremos um mulato em cada grão de areia, para celebrarmos a vossa passagem por este mundo! (CHIZIANE, 2010, p. 67s.).

Tanto nos mitos antigos como nos mitos novos, a usurpação do poder das muIheres pelos homens, não se representa unicamente como uma violação, mas também como um desejo mútuo. Desta maneira, o poder interpretativo tradicional (a mulher do régulo) visa a reconciliação entre os sexos e também entre as "raças". Porém, no tempo mítico absoluto a questão racial ainda não aparece: a comunidade mítica é homogénea: "Na primeira geração éramos da cor da terra: todos negros" (CHIZIANE, 2010, p. 54). Todavia, no tempo histórico mitificado a questão racial já aparece como um elemento novo, que é harmonizado e incorporado na comunidade através da mitificação da "nova raça" mestiça.

Em conclusão, o espaço mítico de $O$ Alegre Canto da Perdiz, na sua qualidade de espaço semântico e cronotópico, se carateriza basicamente por um tempo cíclico (que vai devorando gradualmente o tempo histórico) e uma subdivisão num espaço feminino e masculino. A relação entre os subespaços é conflituosa, mas a separação do espaço feminino e masculino mantém-se intacta, mesmo que se subverta a relação de dominação feminina inicial. Portanto, a "guerra dos sexos" constitui a estrutura primária do texto, apresentada como condição natural e divina e interpretada como motor da procriação e garantia da persistência da comunidade.

18 Tanto La Guardia e Gonçalves (2010, p. 219) como Miranda (2011, p. 9) chamam a atenção sobre esta relação metonímica mulher-Zambézia-África vítima de homem-colonizador-Europa. 


\subsection{0 espaço histórico colonial e pós-colonial}

O passado histórico é relativo. A sua distância do presente em curso alonga-se gradualmente, ao contrário do que acontece com o passado absoluto dos mitos. O espaço histórico do romance abrange os mencionados dois eixos temporais da narração: a época colonial recente e um curto momento da época pós-colonial. Ao contrário dos mitos que são domínio da memória cultural, o tempo histórico recente faz parte da memória comunicativa que abrange as vivências das três ou quatro gerações vivas (ASSMANN, 2007, p. 48-56). Este passado recente apresenta um início temporal concreto na memória:

Mas tudo começou no dia em que o pai negro partiu para não mais voltar. Tudo começou quando o pai branco amou a sua mãe. Tudo começou quando a sua mãe vendeu a sua virgindade para melhorar o negócio de pão. Tudo começou com relação que envolvia sexo e amargura (CHIZIANE, 2010, p. 28).

Estes momentos incisivos na biografia de Maria das Dores, que traz a dor no seu nome, marcam o início do sofrimento individual e, por extensão metonímica, coletivo, causado pelo que chamaremos de "guerra das raças". Esta nova "guerra" não só constitui um conflito entre brancos e negros (portugueses e africanos), mas também potencializa a "guerra dos sexos" subjacente. Enquanto a hierarquia entre os subespaços feminino e masculino é variável (devido à mistura de culturas matrilineares e patrilineares e a conceção do tempo cíclico), a hierarquia entre o subespaço dos negros e dos brancos é rígida e conhece as seguintes escalas: negros comuns ("indígenas"), negros assimilados, mestiços e brancos.

A problemática racial é-nos apresentada a partir da perspetiva dos negros. Sobretudo Delfina, personagem muito ambiciosa, transforma ambas as "guerras" num assunto pessoal. O objetivo primordial dela é a ascensão social ("terei a grandeza das sinhás e das donas, apesar de preta!", CHIZIANE, 2010, p. 81) e a anulação da sua condição de negra ("Amava os brancos. Ela queria ser branca", CHIZIANE, 2010, p. 31). Na linha de Frantz Fanon em Peau noire, masques blancs (1952), La Guardia e Gonçalves (2010, p. 222s.) afirmam que Delfina, na sua condição de sujeito colonizado, desenvolve um comportamento neurótico e constrói uma imagem inferiorizada de si mesma e da sua própria "raça". Para tal, 
ela instrumentaliza e reifica os homens e os seus próprios filhos. Como negra, encontra-se na escala social mais desfavorecida, porém é membro de uma cultura em que as mulheres desempenham papéis mais ativos e têm mais direitos do que nas culturas do sul do país. ${ }^{19}$

Neste conflito socio-racial, o amor e as suas diferentes leituras culturais obtêm novamente um papel importante. Delfina, jovem prostituta, apaixona-se perdidamente por José dos Montes, que the parece indigno de ser o seu marido, não só por ser preto, mas também, pela sua condição de "condenado". Não obstante, "apenas para consumir a paixão" (CHIZIANE, 2010, p. 102), ela decide casar com José: "Então casemos, assim o amor acaba" (CHIZIANE, 2010, p. 92). $\mathrm{O}$ amor não constitui para ela um valor, mas um estorvo no caminho à ascensão socio-racial. Contudo, o amor mítico (paixão-procriação) não perdeu seu vigor, Delfina não consegue negar-se a vivê-lo. Mas a mãe de Delfina, Serafina, tenta opor-se ao casamento, vendo no amor unicamente uma fonte do sofrimento: "Diz-me o que é o amor, para a mulher violada a caminho da fonte por um soldado, um marinheiro ou um condenado? As histórias de paixão, são para quem pode sonhar" (CHIZIANE, 2010, p. 101). Para ela, o amor mítico transformou-se no espaço histórico em eterno sofrimento feminino. E um eventual amor-paixão romântico de corte europeu nesta África colonial parece ser um privilégio só dos brancos. Segundo Serafina, é preciso apagá-lo para atenuar a dor e o sofrimento.

Enquanto Serafina é apresentada como vítima da colonização, Delfina torna-se agente ativa e José dos Montes seu cúmplice involuntário. Depois do casamento ela pede-lhe para ele se tornar "assimilado", exigência que José tenta declinar, consciente do papel ambíguo destes ("Os assimilados são assassinos, Delfina”, CHIZIANE, 2010, p. 122), mas que acaba aceitando por amor, este amor-paixão que mais uma vez é interpretado como fonte de dor. Delfina considera a assimilação o único meio para a ascensão social: "Colonizar é fechar todas as portas e deixar apenas uma. A assimilação era a [sic] único caminho para a sobrevivência" (CHIZIANE, 2010, p. 123). Os trâmites legais da assimilação são

\footnotetext{
19 Na seguinte citação do romance a voz do narrador, ou melhor, da narradora, apregoa as vantagens do matriarcado para as mulheres: "A alegria e a liberdade são filhas do matriarcado, onde se obedecem às leis da natureza, porque só a mulher sabe o verdadeiro pai dos filhos que tem. Os homens são simples reprodutores, seres menores. Por isso eles devem pagar por tudo. Pelo lazer, pelo prazer que é concedido pelas mulheres [...]. A violência é produto do patriarcado, porque os homens roubaram o poder às mulheres" (CHIZIANE, 2010, p. 280).
} 
retratados pela voz da narradora (do narrador) com violência e azedume, tal como comprovam os vocábulos sumamente negativos:

Vamos, jura por tudo, que não dirás mais uma palavra nessa língua bárbara. Jura, renuncia, mata tudo, para nascer outra vez. Mata a tua língua, a tua tribo, a tua crença. Vamos, queima os teus amuletos, os velhos altares e os velhos espíritos pagãos (CHIZIANE, 2010, p. 123).

O espaço histórico é, para os negros, um espaço de sofrimento e de violência não só física, mas também social uma vez que lhes é negado um espaço de representação simbólica e a autoafirmação de uma identidade própria minimamente digna. José, que tenta escapar desta estigmatização, não consegue adotar a nova identidade. $\mathrm{O}$ assimilado dá-se conta de que acaba vivendo num espaço muito precário e instável entre as duas "raças", em palavras de Sheila Khan (2013, p. 208), "um lugar sem enunciação, sem história, sem narração", razão pela qual a partir deste momento a vida de José dos Montes entrará em declínio. Torna-se sipaio e, portanto, traidor, torturador e assassino de homens da sua própria "raça". A assimilação revela-se como "ferramenta de exploração, de submissão e de desapropriação territorial, social e ontológica" (KHAN, 2013, p. 208), e a unidade inicial do povo negro, unidade mítica, quebra-se:

No princípio éramos apenas um. Um povo. Uma família, um exército de resistência. De repente ficámos diferentes. Eles lá e eu do lado de cá. Fizeram-me crer que do lado de lá estava a tristeza e eu creio. Fizeram-me crer que do lado de cá está a nobreza e eu creio (CHIZIANE, 2010, p. 135).

É neste espaço intermédio que os assimilados, seduzidos pelas promessas do discurso hegemônico racista, se tornam culpados não só da morte dos seus iguais, mas também do êxito da colonização em geral ("Sem a cumplicidade dos assimilados e seus sipaios, a terra jamais seria colonizada", CHIZIANE, 2010, p. 139) e mais ainda da destruição da sua unidade mítica por se terem transformado no "Outro". No entanto, Delfina continua lutando impiedosamente pela ascensão social e dá à luz uma criança mulata, filha do colono português Soares ("O meu estatuto é maior a partir de agora! Mãe de mulata. Concubina de um branco", CHIZIANE, 2010, p. 193). Delfina transforma-se num monstro que se 
dedica a destruir a felicidade tanto dos negros como dos brancos, numa luta aparentemente egoísta.

Porém, perde tudo. A sua guerra particular contra o sistema colonial revela-se infrutífera: "Delfina, a rainha! Que desafiou brancos, desafiou o sistema, entrou na guerra, ganhou e perdeu [...]" (CHIZIANE, 2010, p. 277). Consciente de que o seu comportamento foi causa de muito sofrimento, Delfina coloca a questão da culpa. Curiosamente acusa todos os seus próximos, seus pais, seus homens e inclusivamente a si mesma e, portanto, incrimina indivíduos antes do sistema subjacente:

Por culpa da minha mãe que me fez preta e me educou a aceitar a tirania como destino de pobres e a olhar com desprezo a minha própria raça. Por culpa do Simba, meu amante e teu marido, que me alimentou de feitiços e fantasias destrutivas. Por culpa da natureza que me deu beleza sobre todas as mulheres. Por culpa do José, pobre e preto que me alimentava de farinha e peixe seco, enquanto eu, Delfina, queria bacalhau e azeitonas, A culpa é do Soares, que me elevou aos céus e me largou no ar. A culpa foi minha. Por ter desejado ser o que jamais poderia ser. A culpa é do mundo, que me ensinou a odiar (CHIZIANE, 2010, p. 47).

Só na última frase da citação podemos deduzir que Delfina chega a entender vagamente que a culpa é do regime político injusto e da sua ideologia racista. Ao lutar com as próprias armas do sistema para alcançar uma melhor posição dentro do sistema (e não fora), ela fica durante muito tempo impossibilitada de discernir os contornos do verdadeiro culpado. A "guerra das raças", se bem que constitui um processo irreversível na medida em que produz classes sociais e raciais intermédias (os assimilados e os mulatos), não leva ainda à dissolução das linhas divisórias racial-sociais. Inclusive no segundo eixo temporal, a época pós-colonial, continua reinando uma mentalidade colonial:

Trinta anos de independência e as coisas voltam para trás. Assiste ao regressar às raízes. Os filhos dos assimilados ressurgem violentos e ostentam ao mundo o orgulho da sua casta. O colonialismo já não é estrangeiro, tornou-se negro, mudou de sexo e tornou-se mulher. Vive no útero das mulheres, nas trompas das mulheres e o sexo delas se transformou em ratoeira para homem branco (CHIZIANE, 2010, p. 345). 
Nesta reflexão atribuída a José dos Montes (num discurso interior livre), perdedor na "guerra dos géneros" e das "raças", a lógica da estrutura primária, $i$. e., a hierarquia social determinada pelas "raças", transformou-se, mas só a nível epidérmico. Na época pós-colonial a hierarquia social profunda permanece em vigor, mas muda de cor. Os negros comuns continuam sendo os mais desfavorecidos, os escalões mais elevados são ocupados pelos assimilados e mulatos, por aquelas classes que na época colonial estavam mais próximas do poder branco. A "guerra das raças" transforma-se definitivamente em "guerra social".

\subsection{0 espaço do futuro imaginado}

Não é por acaso que as personagens se reencontram no final em Gurué, cidade ao pé dos Montes Namuli, origem cosmogónica: “O céu azul foi chocado nos Montes Namuli, num ovo de perdiz. Nasceu com asas de pássaros, voou e colonizou a terra inteira [...]. É aqui o princípio do mundo. O fim do mundo. Todas as raças nasceram aqui" (CHIZIANE, 2010, p. 338s.). O mito que dá título ao romance conta a criação do mundo antes de qualquer conflito humano. É a este lugar que as personagens regressam simbolicamente: o lugar do (re)começo.

O espaço do futuro imaginado, do recomeço, testemunha o desejo do povo moçambicano, que vivenciou a guerra colonial (1964-1974) e a guerra civil (1977-1992), de viver em paz. As personagens imaginam um futuro harmonioso em que as três "guerras" mencionadas na análise, a dos sexos, das "raças" e a social, acabam por se transformar numa relação de amor. No espaço histórico colonial o amor era interpretado como um estorvo na vida dos negros, fonte de sofrimento, e privilégio dos brancos. A visão do futuro, porém, parte da afirmação da universalidade do amor: "Não vale a pena tanta guerra. Nas coisas do amor, todas as raças são iguais" (CHIZIANE, 2010, p. 55), e reinterpreta a "guerra das raças" como uma "guerra dos sexos":

Os brancos estavam aqui, ao lado dos pretos. Amando-se e odiando-se como marido e mulher dentro de uma casa. Mas a zanga e divórcio, sucumbiram ao milagre do tempo: $\mathrm{O}$ ódio de ontem transforma-se num novo amor e a saudade na emergência de uma nova união (CHIZIANE, 2010, p. 59s.). 
A relação entre colonizador e colonizado é comparada a um casamento em que a paixão e o amor se transformam, num movimento cíclico, em ódio, violência e levam depois à reconciliação. Portanto, aqui reaparece a regra de alternância mítica.

Mas não só o amor mítico e tradicional, a paixão-procriação, irmana as "raças", também a violência acaba criando uma união identitária desde que constitui uma convivência extremamente intensa que, na perspetiva de uma tradição africana, apresenta uma dimensão espiritual:

O assassino encarna o espírito da sua vítima. O preto que matou o branco, partirá de joelhos para a terra do branco. Para pagar a dívida de sangue na árvore dos antepassados do morto. Os brancos que mataram voltarão. Para se ajoelharem e pedir o perdão aos nossos antepassados. E serão recebidos nas nossas palhotas como irmãos. O sangue derramado irmana, faz um nó e nem a morte pode separar (CHIZIANE, 2010, p. 61).

Segundo esta cosmovisão africana, cria-se um laço sanguíneo tanto na morte violenta como na procriação da vida. Amigo e inimigo irmanam-se numa união espiritual, contra si mesmos.

Além disto, as personagens anelam ainda a re-harmonização racial, que já foi tema dos novos mitos situados no tempo histórico. Como no início, em que "todos éramos negros", agora a "nova raça" converte-se em condição inalienável para um futuro harmonioso: "É preciso que haja mais guerras até que os pretos e brancos se misturem apenas numa só raça. E numa só nação" (CHIZIANE, 2010, p. 138). Aqui surge a visão utópica de uma "raça" mestiça homogénea que reencaminharia os moçambicanos às origens míticas da Zambézia. Nesta utopia já não haveria racismo, nem "guerra social", porque outra vez todos seriam iguais. O único conflito que prosseguiria seria a eterna "guerra dos sexos". ${ }^{20}$ Por conseguinte, o tempo deste espaço semântico é um futuro absoluto, que se mantém sempre na mesma distância inalcançável do presente (igual ao passado

\footnotetext{
20 Para La Guardia e Gonçalves "Delfina conclui que a mestiçagem tão desejada não deve residir na homogeneidade ou na substituição de uma raça por outra, mas no reconhecimento e na valorização da diversidade" (2010, p. 223). Contrariamente ao que as autoras afirmam, não acreditamos que Delfina chegue a uma verdadeira "valorização da diversidade", mas apenas a uma utópica proclamação de um novo tempo mítico harmonioso.
} 
absoluto).

O espaço do futuro visa o regresso ao tempo mítico. Desta forma, o espaço histórico aparece como um hiato doloroso que será ultrapassado. O novo mito alicerça o futuro e cria uma identidade nacional que harmoniza todos os elementos que estavam em luta. Portanto, as personagens não constroem uma identidade moderna, capaz de entender e aceitar diferenças internas, mas uma apologia da miscigenação e uma identidade homogénea típica de sociedades tradicionais.

\section{Conclusão}

A sociedade retratada no romance de Paulina Chiziane apresenta caraterísticas profundamente tradicionais e dispõe de mecanismos próprios para lidar com conflitos. As culpas dos conflitos violentos são distribuídos por partes iguais, num vai e vem alternado: logo vencem os homens, depois as mulheres, às vezes os brancos, às vezes os negros. Paulina Chiziane constrói uma conceção da história fluida, em que a alternação parece ser a eterna regra. E é, justamente, esta alternação a culpa distribuída por igual, que possibilita o perdão e a reconciliação. Desta maneira, a distinção entre vítimas e culpados esvazia-se de sentido, e até a personagem mais cruel do romance, Delfina, vai sendo desculpada pela sua primeira vítima, José dos Montes: "A culpa não foi nada tua, Delfina. Fomos um homem e uma mulher na construção do mundo" (CHIZIANE, 2010, p. 343). Esta sociedade tradicional conhece mecanismos de reconciliação íntimos, abrangentes e, sobretudo, muito diferentes das sociedades modernas que anelam uma reparação pública e oficial efetuada pelo Estado, e não por um poder interpretativo no microcosmos das aldeias como o griot. Ao passo que os empenhos de homogeneização da Frelimo ${ }^{21}$ visavam a transformação rápida do presente com

21 Desde a sua fundação, a Frelimo esforçou-se por homogeneizar o "povo" e construir uma unidade nacional. Durante a presidência de Samora Machel, o "pai da nação" (1975-1986), a imagem do inimigo comum, isto é, os vestígios do colonialismo português, continuavam a servir de elemento unificador, ao lado da introdução do ideal do Homem Novo socialista que rejeitava o racismo, o tribalismo e o regionalismo. A Frelimo perseguia uma nova política assimilacionista, já não à imagem da cultura portuguesa, mas à do Homem Novo, tentando apagar assim a diversidade cultural e das forças sociais ativas no mundo rural (Rocha, 2013, p. 131-134). Esta linha mantevese basicamente até ao início dos anos 1990. 
vistas ao futuro imediato, a imaginada homogeneização socio-racial do romance visa um futuro absoluto, inalcançável, utópico e, portanto, mítico. A tentativa da Frelimo de assimilar o povo ao ideal do Homem Novo afinal de contas fracassou, por tratar-se de uma ideia moderna e urbana, mais conveniente a uma sociedade "quente" que deseja o progresso e a transformação, enquanto a sociedade moçambicana, na sua dimensão rural, é basicamente tradicional, isto é, "fria", porque pretende o equilíbrio e a continuidade, aguentando simultaneamente a heterogeneidade do presente, interpretada como etapa transitória. 


\section{Referências}

ASSMANN, Jan. Das kulturelle Gedächtnis. Munique: H. C. Beck, 2007 [1992].

BAKHTIN, Mikhail. Forms of time and the chronotope in the novel. In: HOLQUIST, Michael (ed.). The dialogic imagination: four essays by M. M. Bakhtin. Tradução: Caryl Emerson e Michael Holquist. Austin: University of Texas, 1981. p. 84-258.

BRAGA, Juliana Primi. Entre dois mundos: a loucura feminina nos romances A Louca de Serrano, de Dina Salústio, e O Alegre Canto da Perdiz, de Paulina Chiziane. 140 p. Tese. Universidade de São Paulo, São Paulo, 2013. Disponível em: <http://www.teses. usp.br/teses/disponiveis/8/8156/tde-10032014-104439/en.php>. Acesso em 24 de março 2015.

CASTELO, Cláudia. O modo português de estar no mundo: O luso-tropicalismo e a ideologia colonial portuguesa (1933-1961). Porto: Afrontamento, 2011 [1999].

CHIZIANE, Paulina. O Alegre Canto da Perdiz. Maputo: Ndjira, 2010 [2008].

COSTA, Pollyana dos Santos Silva. A mulher moçambicana e a assimilação na obra de Paulina Chiziane. In: XIV SEMINÁRIO NACIONAL MULHER E LITERATURA / V SEMINÁRIO INTERNACIONAL MULHER E LITERATURA. 2011, Brasília. Anais. Brasília: Universidade de Brasília, 2011. Disponível em: <http://www.telunb.com.br/mulhereliteratura/anais/wp-content/uploads/2012/01/pollyana_santos.pdf>. Acesso em 24 de março 2015.

HALL, Stuart. A identidade cultural na pós-modernidade. Tradução: Tomaz Tadeu da Silva, Guacira Lopes Louro Rio de Janeiro: DP\&A, 2006.

KHAN, Sheila. Pedir licença na terra que é nossa: A miséria da colonialidade em $O$ Alegre Canto da Perdiz. In: MIRANDA, M. G. de / SECCO, C. L. Tindó (orgs.). Paulina Chiziane: Vozes e rostos femininos de Moçambique. Curitiba: Appris, 2013, p. 203-216.

LA GUARDIA, Adelaine / GONÇALVES, Anamélia Fernandes. Corpos transfigurados: Uma análise do corpo mestiço em $O$ alegre canto da perdiz, de Paulina Chiziane. In: IPOTESI, Juiz de Fora, v. 14, n. 2, p. 215-226, 2010. Disponível em: <http://www.ufjf.br/ revistaipotesi/files/2011/04/18-Corpos-transfi-gurados.pdf>. Acesso em 24 de março 2015.

LOTMAN, Jurij M. Die Struktur literarischer Texte. Munique: Wilhelm Fink, 1993 [1972]. MIRANDA, Maria Geralda de. A África e o feminino em Paulina Chiziane. In: Mulemba, v. 1, n. 2, UFRJ, Rio de Janeiro, p. 62-70, 2010. Disponível em: <http://setorlitafrica.letras.ufrj.br/mulemba/artigo.php?art=artigo_2_6.php>. Acesso em 24 de março 2015.

MIRANDA, Maria Geralda de. Percursos e identidades culturais em países de língua portuguesa. In: XI CONGRESSO LUSO AFRO BRASILEIRO DE CIÊNCIAS SOCIAIS, 2011, Salvador. Anais. Salvador: Universidade Federal da Bahia, 2011. p. 1-11. Disponível 
em: $\quad$ <http://www.xiconlab.eventos.dype.com.br/resources/anais/3/1306086704_ ARQUIVO_PERCURSOSEIDENTIDADESCULTURAISEMPAISESDELINGUAPORTUGUESA-22-05-2011.pdf>. Acesso em 24 de março 2015.

NASCIMENTO, Amanda Siqueira do / BOTELHO, Amara Cristina de Barros e Silva. Os perfis femininos em $O$ Alegre Canto Da Perdiz, de Paulina Chiziane. In: Revista Encontro do Gabinete Português de Leitura de Pernambuco, Recife, n. 24, p. 39-49, 2013. Disponível em: <http://www.interpoetica.com/pdf/revista_encontro_2014.pdf\#page=39>. Acesso em 24 de março 2015.

ROCHA, Aurélio. A 'questão nacional' em Moçambique. In: NASCIMENTO, A. / ROCHA, A. (orgs.): Em torno dos nacionalismos em África. Maputo: Alcance, 2013, p. 121-158. TEIXEIRA, Ana Luísa Valente Marques. 'Não sou mesmo uma feminista?' A política do corpo em $O$ alegre canto da perdiz, de Paulina Chiziane. In: Mulemba, v. 1, n. 2, UFRJ, Rio de Janeiro, p. 71-82, 2010. Disponível em: <http://setorlitafrica.letras.ufrj.br/mulemba/artigo.php?art=artigo_2_7.php>. Acesso em 24 de março 2015.

ZAMPARONI, Valdemir. A política do assimilacionismo em Moçambique, c. 1890-1930. In: DELGADO, I. G. / ALBERGARIA, E. / RIBEIRO, G. / BRUNO, R. (org.): Vozes (Além) da África: Tópicos sobre identidade negra, literatura e história africanas. Juiz de Fora: UFJF, 2006, p. 145-175.

ZAMPARONI, Valdemir. Entre Narros \& Mulungos. Colonialismo e paisagem social em Lourenço Marques. c. 1890 - c. 1940. 582 p. Tese. Universidade de São Paulo, 1998. Disponível em: <http://macua.blogs.com/files/entre-narros-mulungos---colonialismo-e-paisagem-social-em-louren\%C3\%A7o-marques-1890-1940.pdf>. Acesso em 24 de março 2015. 